\title{
Whole-Cell Bioprocessing of Human Fetal Cells for Tissue Engineering of Skin
}

\author{
L.A. Applegate ${ }^{a, c} \quad$ C. Scaletta ${ }^{a, c} \quad$ N. Hirt-Burria ${ }^{a} \quad$ W. Raffoul ${ }^{b}$ D. Pioletti ${ }^{c}$ \\ ${ }^{a}$ Cellular Therapy Unit, Department of Musculoskeletal Medicine (DALO) and b Surgerie Plastique et Reconstructive, \\ Centre Hospitalier Universitaire Vaudois, CHUV-UNIL, and ' Laboratoire de Biomécanique en Orthopédie \\ (EPFL-DALO), École Polytechnique Fédérale de Lausanne, Lausanne, Switzerland
}

\section{Key Words}

Tissue engineering • Fetal skin • Cellular therapy •

Wound healing

\begin{abstract}
Current restrictions for human cell-based therapies have been related to technological limitations with regards to cellular proliferation capacity (simple culture conditions), maintenance of differentiated phenotype for primary human cell culture and transmission of communicable diseases. Cultured primary fetal cells from one organ donation could possibly meet the exigent and stringent technical aspects for development of therapeutic products. Master and working cell banks from one fetal organ donation (skin) can be developed in short periods of time and safety tests can be performed at all stages of cell banking. For therapeutic use, fetal cells can be used up to two thirds of their life-span in an outscaling process and consistency for several biological properties includes protein concentration, gene expression and biological activity. As it is the intention that banked primary fetal cells can profit from the prospected treatment of hundreds of thousands of patients with only one organ donation, it is imperative to show consistency, tracability and safety of the process including donor tissue selection, cell banking, cell testing and growth of cells in out-scaling for the preparation of whole-cell tissue-engineering products.
\end{abstract}

Copyright $\odot 2009$ S. Karger AG, Basel

\section{KARGER}

Fax +4161306 1234

E-Mail karger@karger.ch

www.karger.com
(C) 2009 S. Karger AG, Basel

$1660-5527 / 09 / 0222-0063 \$ 26.00 / 0$

Accessible online at:

www.karger.com/spp

\section{Introduction}

Cell-based therapies can now be seen in routine medical care and especially for wound management of skin. They offer the promise of repairing and/or replacing damaged tissue and restoring lost functionality. Several cell types and tissues have been proposed as starting material for elaborate tissue engineering processing, including autologous skin cells, adult stem cells, bone marrow, platelets, embryonic stem cells, cadaver skin, acellular dermis, de-epidermized dermis, allogenous full-thickness skin substitutes and xenografts [1-9]. Their clinical uses have extended significantly to a wide variety of indications including burns, acute and chronic wounds, skin loss, surgical wounds and bullous diseases [10-13].

One of the major challenges for assuring that more patients will benefit from tissue engineering in the future is the optimization of the choice of cell type as well as their isolation and proliferation. Equally important is the delivery system of chosen cells and their interaction with scaffolds to create a three-dimensional tissue. Allogenic skin products available for therapeutic usage are mostly developed with cell culture and foreskin tissue of young individuals.

The dermal fibroblasts from foreskin cells have been used in products such as Dermagraft ${ }^{\circledR}$, TransCyte ${ }^{\circledR}$ and ICX-SKN ${ }^{\circledR}$, and all clinical data show that these products

Dr. Lee Ann Laurent-Applegate

Cellular Therapy Unit, Department of Musculoskeletal Medicine, University Hospital CHUV, PAV 03

CH-1011 Lausanne (Switzerland)

Tel. +41 2131435 10, Fax +41 2188784 14, E-Mail Lee.Laurent-Applegate@chuv.ch 
alone are not capable of full wound closure in a short period of time but are predominantly used for wound coverage while waiting for split or mesh grafting [14, 15]. When fetal skin fibroblasts have been used alone in similar delivery systems (native collagen), it was shown that no other surgical means or grafting techniques were necessary for burns and wounds $[12,13]$. The differences in these clinical outcomes could be related to many factors and it is most likely the fetal fibroblast itself that is responsible. Fetal skin cells could offer an ideal solution for effective and safe tissue engineering for wounds of all natures.

Here, we will address important aspects of fetal cell therapy including donor selection (only a single organ donation necessary), cellular out-scaling (master and working cell banks) and defining reproducible processes for fetal cell biological bandage production to be used for treatments of acute and chronic wounds.

\section{Quality of Wound Healing in Fetal and Adult Skin}

\section{Extracellular Matrix Implications}

Considerable interest and research has been dedicated to the understanding of wound healing and the associated process. Whereas adult cutaneous wounds heal with scar formation to restore tissue integrity, fetal skin in utero is observed to have rapid and scarless tissue repair characterized by regeneration of an organized dermis with normal appendages and by a relative lack of inflammation [16-18]. Fetal wound healing and its transition from scarless repair to healing with scar formation is situated at a threshold around 24 weeks of gestation in humans. The reason for this transition is thus strategic in the understanding of specific mechanisms of scarless wound healing.

Fundamental differences between fetal and adult skin as well as the fetal and adult skin wound environment may be important in inducing scarfree tissue repair. Early in gestation, the dermis is thin, relatively acellular and a low extracellular matrix (ECM) is present. During further development, dermal collagen is deposited and sulfated glycosaminoglycans replace hyaluronic acid among other nonsulfated glycosaminoglycans. The extremely rapid growth and the loose ECM provide a conducive territory for scarless fetal skin repair [19]. In large animal and human models, scarless repair occurs during specific periods of gestation, from midgestation to the early third trimester. There is a transition period between scarless and scar-forming repair, scarless healing also de- pends on the organ involved. In skin, scarless healing in the fetus is characterized by regeneration of an organized dermis with normal appendages and by a relative lack of inflammation. Another line of evidence showing that it is indeed fetal skin cells themselves that are responsible for scarfree tissue repair is that the in utero environment does not seem to be essential nor sufficient for scarless fetal repair. Fetal skin outside the warm, sterile, growth factor-rich amniotic environment has been shown to be very efficient in scarless and rapid healing. This has been demonstrated with an opossum model as this marsupial is born fetal like, both physiologically and anatomically, and remains attached to the mother's nipple for $4-5$ weeks [18]. Despite their extrauterine location, wounds in earlypouch young re-epithelialize very quickly, synthesize collagen and heal without scar. In contrast, wounds in older-pouch young heal more slowly and with scar formation. In this same line, human fetal skin transplanted subcutaneously to an immunoincompetent mouse retained its developmental characteristics and healed without scar along with restoration of hair follicules and reticular collagen arrangement [20]. As the regenerative capabilities of human fetal skin were not disrupted by an adult extrauterine wound environment or contact with adult mouse blood, the scarless capacities appear to be intrinsic to the fetal tissue itself, and the fetal dermal cells themselves are most likely the main effectors of scarless healing in fetal tissue.

Fetal fibroblasts have the capacity to deposit wound collagen in a fine, highly organized pattern that is indistinguishable from the surrounding uninjured dermal collagen. The fibroblasts themselves are the principal source of collagen which is the major component of ECM [21].

Differences between scarring and scarless collagen architecture may be partially explained by differences in collagen profiles between fetal and adult fibroblasts. In human fetal skin, collagen type III comprises $30-60 \%$ of the total, in adult skin $10-20 \%$. Collagen type III fibers are smaller and finer than type I fibers, whereby the higher portion of type III fibers may allow a more reticular pattern of fiber deposition. With increasing age of gestation, the relative collagen ratios in fetal skin approach that of adults, correlating with the transition from scarless repair to scar formation. In addition to collagen, a different profile of glycosaminoglycan and protoglycan synthesis can be observed in fetal ECM. Early gestational fetal skin is rich in hyaluronic acid (a glycosaminoglycan) and fibromodulin (a protoglycan), but poor in decorin (protoglycan) compared to matured fetal skin or adult 
skin [20]. Fetal fibroblasts can simultaneously proliferate and synthesize collagen, and the migration of these cells into a wound is thought to be involved in replacing the ECM in tissue repair either directly or indirectly by stimulating host tissue. Migration is an important fibroblast response following tissue injury and is crucial to the repair process. Fetal fibroblasts possess more rapid intrinsic rates of migration than those seen in adult skin fibroblasts.

Scarless fetal wounds heal with little inflammation, and the onset of scarring during fetal repair correlates with the presence of an acute inflammatory infiltrate [22]. In addition, introduction of inflammation into normally scarless-healing wounds results in increases in collagen deposition and scarring. This suggests an important function of inflammation during scar formation. As the immune system develops and its resulting inflammatory response increases, scar formation occurs at the repair site. Synthesis and remodeling of the ECM by wound fibroblasts is likely the major determinant of dermal architecture after repair. Differences between scarring and scarless collagen architecture may be partly explained by phenotypic differences between adult and fetal fibroblasts.

\section{Molecular Analysis of Scarless Wound Healing}

Molecular analysis of wound healing has largely been devoted to cytokines and most particularly those of the transforming growth factor (TGF) family and their role in manipulating cutaneous wound healing and scar formation. It has been suggested that scarless wound healing in fetal skin at early gestation is a result of the unique cytokine or grow th factor profile. Of these, TGF- $\beta$ has been most widely studied as it is implicated in the transition between scarless healing and repair with scar formation. In this process, growth factors' main functions are to control cell proliferation and differentiation and to stimulate the synthesis of ECM such as collagen. Three highly homologous TGF- $\beta$ isoforms are known in humans: $\beta 1, \beta 2$ and $\beta 3$. Each form has been found by immunohistochemistry in unwounded fetal skin. However, low levels of TGF- $\beta 1$ and high levels of TGF- $\beta 3$ are expressed at gestational ages associated with scarless repair. In addition, it appears that the relative proportion of TGF- $\beta$ isoforms, and not the absolute concentration of any one isoform, determines the wound repair outcome $[23,24]$.

Exogenous application of TGF- $\beta 1$ to normally scarless fetal wounds resulted in scar formation with an adultlike inflammatory response observed. The profibrotic nature of TGF- $\beta 1$, and possibly TGF- $\beta 2$, was confirmed in wounds of adult rats, since neutralizing TGF- $\beta 1$ and
TGF- $\beta 2$ with antibodies partially reduced the amount of scarring. TGF- $\beta 1$ stimulates collagen I production, which is the predominant collagen type in adult skin. On the other hand, supplementation with TGF- $\beta 3$ reduced scarring and inflammation in adult wounds confirming its potential antifibrotic properties. The fact that scarless fetal wounds heal with little inflammation and that the onset of scarring during fetal repair correlates with the presence of an acute inflammatory infiltrate, may be related to the pronounced anti-inflammatory properties of TGF- $\beta 3$.

However, TGF- $\beta 1$ - and TGF- $\beta 2$-neutralizing antibodies do not entirely prevent scarring in the adult, and other studies question the efficacy of TGF- $\beta 3$ in wound healing [25-27]. This suggests that factors other than TGF- $\beta$ may also be important in scarless repair. As wound healing is very complex, there are certainly many other molecules within the TGF- $\beta$ superfamily which could have a role. For instance, ECM constituents fibromodulin or decorin, which are expressed as a function of gestational age in fetal skin, are known to modulate TGF$\beta$ activity. Bone morphogenic protein (BMP) family of genes and their receptors are among those in the TGF- $\beta$ superfamily genes and have also been strongly associated with cutaneous wound healing and scarless wound healing in the fetus. More recent studies have shown evidence for the importance of angiogenesis and nerve formation in wound repair involving pleiotropin (PTN) and midkine (MK), two members of the Ptn/Mk developmental gene family which are also in the TGF- $\beta$ superfamily [28-30].

By selecting families of genes that have been reported to be implicated in wound repair and particularly for scarless fetal wound healing, including the TGF- $\beta$ superfamily, ECM and nerve/angiogenesis growth factors, we have analyzed differences in their expression between fetal skin and foreskin cells and the same passages. Of the 5 TGF- $\beta$ superfamily genes analyzed by real-time RT-PCR, 3 were found to be significantly different with 6 -fold upregulation for TGF- $\beta 2$ and 3.8-fold for BMP- 6 in fetal cells, whereas GDF-10 was 11.8-fold downregulated. For nerve growth factors, MK was 36.4-fold downregulated in fetal cells and PTN was 4.76-fold upregulated (table 1).

By studying the differences between fetal skin cells and other cell types already therapeutically used in humans since several years, it may be possible to identify important markers in gene families known to have an impact in this complex process, and these differences in gene expression could contribute to the degree of efficiency seen in clinical use with these cells. 
Table 1. Regulation of genes in cells from fetal skin versus foreskin and their biological process

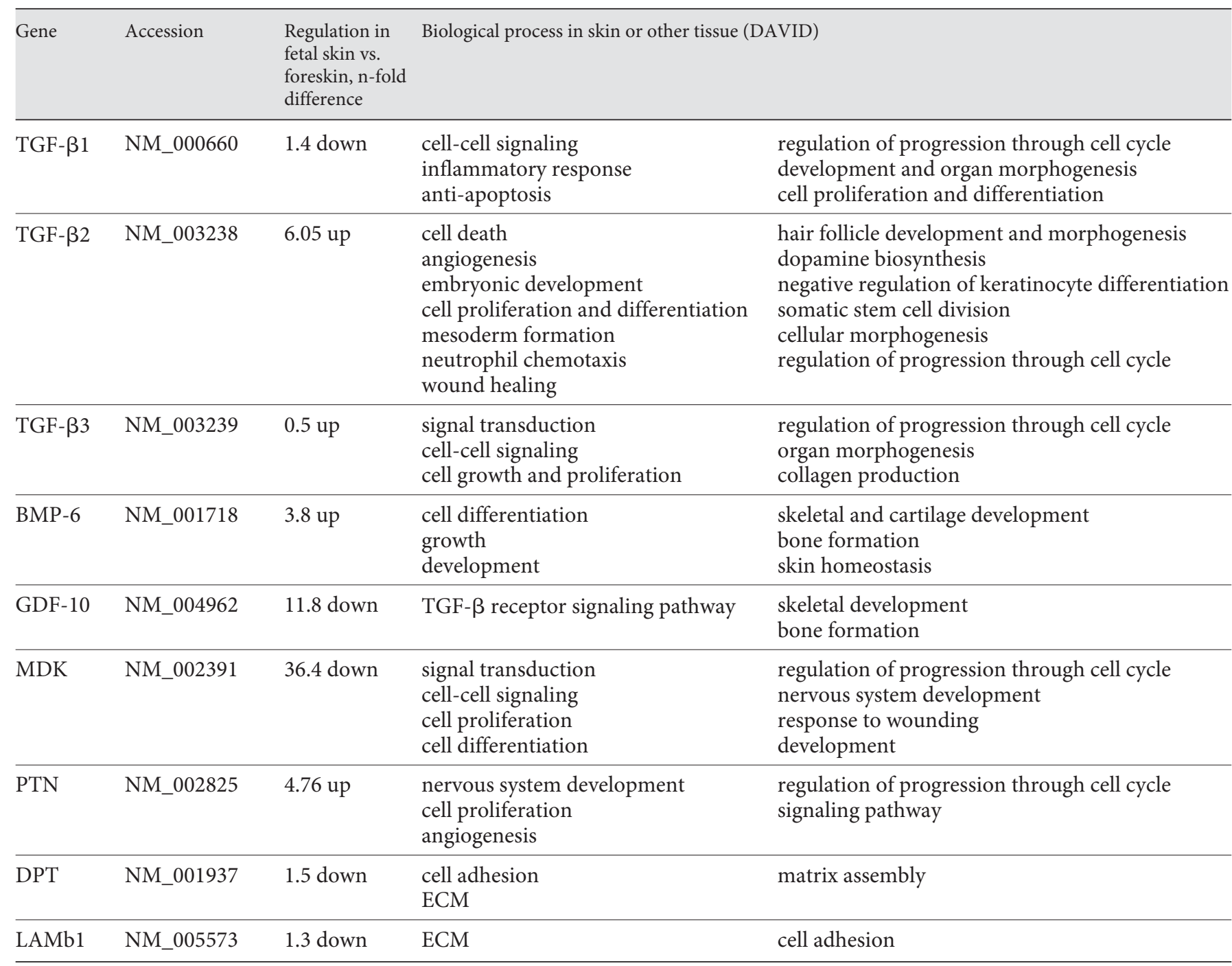

\section{Cell Choice in Out-Scaling for Tissue Engineering}

Fetal cells offer many advantages over other cell choices for tissue engineering and these are summarized in table 2. Fetal skin cells, at the age and passages used for cellular therapy in biological bandages, have been shown to be efficient in total skin repair for burns and wounds.

\section{Technical Requirements}

Fetal skin cells offer an ideal solution for effective and safe tissue engineering for wounds of all nature for several reasons, including (1) cell expansion capacity from one organ donation, (2) minimal cell growth requirements, (3) adaptation to biomaterials for delivery and (4) resistance to oxidative stress. Firstly, fetal skin cells have extensive expansion possibilities as it requires only one organ donation (1-4 $\mathrm{cm}^{2}$ tissue) to create enough frozen cells to produce a bank capable of making over 270 million fetal skin constructs $(9 \times 12 \mathrm{~cm}$, TissueFleece; Baxter). Secondly, cell culture requirements are minimal compared to stem or mesenchymal cell types. As the fetal skin cells are already differentiated and do not need to be directed or altered, the vast numbers of additional growth factors normally necessary are not needed for cell culture and expansion. Similar procedures that exist industrially for vaccine preparation can be implemented for up-scaling of fetal cells. Indeed, the polio vaccine was developed with the use of fetal kidney cells already in 1950. For cell 
Table 2. Requirements for an ideal cell source for skin tissue engineering applications

\begin{tabular}{|c|c|c|c|c|c|c|c|}
\hline & collection & culture & expansion & storage & $\begin{array}{l}\text { skin } \\
\text { formation }\end{array}$ & $\begin{array}{l}\text { no immunologi- } \\
\text { cal reaction }\end{array}$ & $\begin{array}{l}\text { no pro-inflamma- } \\
\text { tory reaction }\end{array}$ \\
\hline Bone marrow cells & ++ & NA & NA & NA & + & ++ & ++ \\
\hline Mesenchymal stem cells & + & ++ & ++ & ++ & +-++ & ++ & ++ \\
\hline Adult stem cells & + & ++ & + & + & ++ & ++ & ++ \\
\hline
\end{tabular}

A high compliance to the requirement is denoted by +++ , while NA means nonadequate.

The immunological reaction refers to the use of cells in an allotransplantation.

banking, careful selection of a donor and an extensive screening of both the donor and cultured cells to avoid transmissible viral, fungal or bacterial disease provide a safe and secure utilization of fetal cells for therapeutic usage.

In addition, fetal cells, unlike neonatal, young or adult cells, adapt particularly well to biomaterials, allowing efficient and simple delivery to the patient. In our laboratory and in others, it has been shown that cells from donors (neonatal to adult) are not capable of efficient integration into various biomaterials and some biomaterials are in fact toxic to the cell. Ng et al. [31] and Monjovent et al. [32] have emphasized that physical characteristics of scaffolds such as porosity and mechanical stability are important for withstanding cell contraction forces and assuring a homogenous distribution of cells throughout the scaffold. It is true that the scaffold is very important for tissue engineering, but the cell type is most probably the limiting factor. We have seen that fetal cells adapt well to various biomaterials $[13,32]$. For processing of a final product for clinical delivery, both the homologous distribution and the rapidity of development of the final product are major significant advantages. When long culture periods are necessary, as for autologous grafting or for the skin products commercially available to date, there is a nonnegligible increased risk for contamination. It is also important to have a process that is consistent and easily repeatable. By developing consistent cell banks with fetal cells, many of the risk factors can be eliminated for bringing safe and effective human cell-based therapies to the bedside.

Along with their rapid growth, simple cell culture requirements and ease of association with bioscaffolds, fetal cells have been shown to be highly resistant to oxidative and physical stresses, making them highly suitable for hostile wound environments [13]. These cells may be more efficient in scavenging potential damaging free radical intermediates or perhaps they are more efficient in processing and repairing oxidative damage to critical cellular targets. Fetal cells can survive at lower oxygen tensions than adult cells and possess more resistance to ischemia during in vitro manipulations. This along with the lack of strong intercellular adhesion in fetal cells render them more resistant to refrigeration and cryopreservation techniques than adult cells [13]. Indeed, in our laboratory, we see a recovery of frozen cells between 95 and $99 \%$, whereas the rates of recovery of young and adult cells are easily $10-15 \%$ lower.

\section{Therapeutic Requirements}

Importantly, three-dimensional cutaneous tissue allografts developed from fetal skin banks show for the first time that a biological skin substitute is capable of providing a very high quality of skin repair/replacement in a short period of time with no additional grafting technique necessary and no immunological or pro-inflammatory reaction seen in any of the clinical studies $[12,13$, 32]. More recently, it has been shown that, when grafts are prepared with a majority of dermal fibroblasts in proportion to keratinocytes, the stimulation of healing is much greater [6].

The need for dermal components to avoid secondary scar contraction and to assist in a good esthetic and mechanical result of tissue repair has been well accepted [33].

It is thus perhaps related to the age of the fetal dermal fibroblasts (14 weeks of gestation) that are used alone, as they are capable of providing total wound closure without any secondary grafting technique necessary. 
Ethical Aspects of Working with Human Fetal Cells

Although there is high medical support for developing cellular-based therapies to reach as many patients as possible, there exists a governing political controversy. Scientists and medical doctors have used fetal tissue since the 1930s as a means to understand cell biology and as an essential tool in the development of vaccines. The 1954 Nobel Prize for Medicine was awarded to immunologists who developed the polio vaccine using cultures of human fetal kidney cells. The political environment changed drastically in 1988 when scientists began using fresh fetal tissue and cells for transplantation into patients with Parkinson's disease. Unfortunately, the Reagan administration (US government) declared a moratorium on all federal funding for fetal tissue research. Advances in fetal cell research were then left only to the private sector where there is no medical peer review of adapted therapies. Indeed, if research on whole-cell bioprocessing of many fetal tissues could have continued, there certainly would have been advances in the amount of tissue necessary for developing efficient therapies (such as with fetal skin where only one organ donation is necessary to allow for cellular expansion to develop over 270 million fetal cell constructs). In Switzerland and most other countries, fetal skin is considered as an organ donation by law. This process is highly regulated, including federal approval for tissue biopsy, stocking and transplantation as well as ethics committee approval of the procedure and all information for the donor. Even though termination of pregnancy is legally allowed, there will always be strong opponents, meaning that the laws and practices remain patient centered (conditions which permit to end an unwanted pregnancy in the best possible way and without unnecessary suffering; www.fiapac.org/e/Links1.html).

\section{Processing of a Fetal Cell Bank and Tissue-Engineered Product}

Specific cell culture from biopsy material has been previously described elsewhere $[13,14]$ and is summarized in figure 1. Briefly, fetal skin biopsies were cleaned of adherent tissue, washed 3 times for 15 min each in phosphate-buffered saline $\left(\mathrm{NaCl} 6.80 \mathrm{~g} / \mathrm{l}, \mathrm{Na}_{2} \mathrm{HPO}_{4}\right.$ $\left.1.48 \mathrm{~g} / \mathrm{l}, \mathrm{KH}_{2} \mathrm{PO}_{4} 0.43 \mathrm{~g} / \mathrm{l}\right)$, dissected and put into culture in tissue culture-grade plates $(60 \mathrm{~cm}$; Falcon). Once the adherent cells reached $80 \%$ confluence, they were trypsinized (EDTA and trypsin solution; Gibco), amplified and ampoules of cells in $1 \mathrm{ml}$ of freezing medium $(50 \%$ DMEM, 40\% FCS, 10\% DMSO) were stored in liquid ni- trogen. Cell banks were stored in the vapor phase of alarm-fitted (to assure sufficient liquid nitrogen) liquid nitrogen storage vessels (Carbagas) rather than in the liquid phase, and portions of each cell bank were split between different vessels in separate locations for security. Although very extensive data tracking is essential for good manufacturing practice records, for our laboratory cell banks, we have prepared a certificate of analysis for each cell bank, giving its designation, number of ampoules prepared, date, tests performed, specification and results. Ampoules were labeled with the cell bank code and each ampoule was individually numbered. Logbooks were used to record all ampoule movements including the initial deposit of the cell bank and also each time an ampoule was removed whether for testing or for experimental purposes. These changes were signed and dated in the cell bank logbook.

The master cell bank (MCB) of 1 cell line destined for clinical use was characterized and extensively tested in the good manufacturing practice facilities of Bioreliance in Glasgow, UK, to demonstrate the absence of viruses. Testing requirements were based on those required for human diploid cells used for vaccine production and for cell substrates used for biotechnological products. Although the donor is obviously human, isoenzyme testing to show Caucasian human origin is necessary for documentation. Other tests were sterility, mycoplasma and retroviral reverse transcriptase activity (FPERT assay). Examinations for viruses, virus-like particles, mycoplasmas, fungi, yeasts and bacteria were done with a minimum of 200 cell profile with quantitative transmission electron microscopy. In vitro testing of picornavirus, orthomyxovirus, paramyxovirus, herpesvirus, adenovirus and reovirus was accomplished with several control cell lines. In vivo virus testing was completed using suckling mice, adult mice, guinea pigs and embryonated eggs. Human virus detection was screened using Q-PCR for the following viruses: HepB, HepC, HIV-1, HIV-2, HTLV-1, HTLV-2, HHV-6, HHV-7, HHV8, EBV, hCMV and SV40. B19 parovirus was also screened with Q-PCR. Safety testing of the working cell bank (WCB) for preclinical and research projects can then be somewhat limited compared to the MCB safety testing, since each MCB ampoule results in a full WCB. Safety testing for laboratory research-developed cell banks needs to be continually controlled for mycoplasma and bacterial contamination.

Regarding the use of the cells for preclinical trials only, it will be particularly important to ensure consistency of growth of the cells and consistency of the harvest ob- 


\section{Cell bank preparation and stockage}

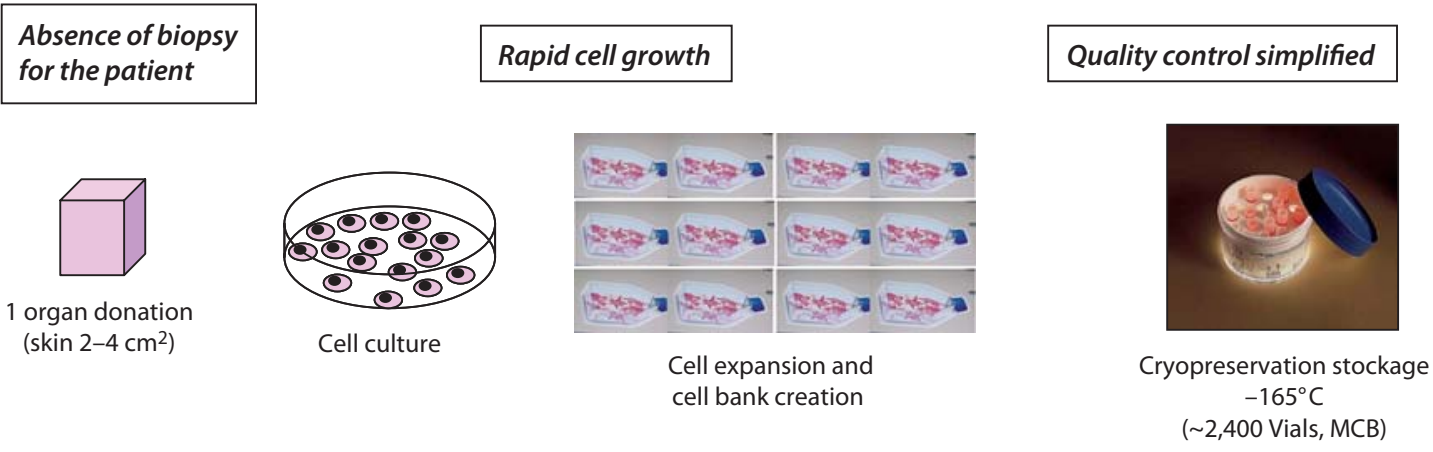

Tissue engineering and patient treatment

Simple preparation and application

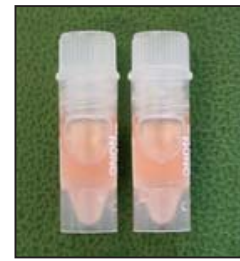

Cells from WCB

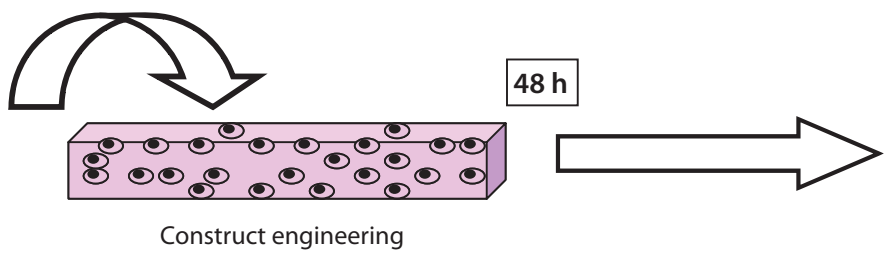

Construct engineering
No staples, glue or sutures necessary

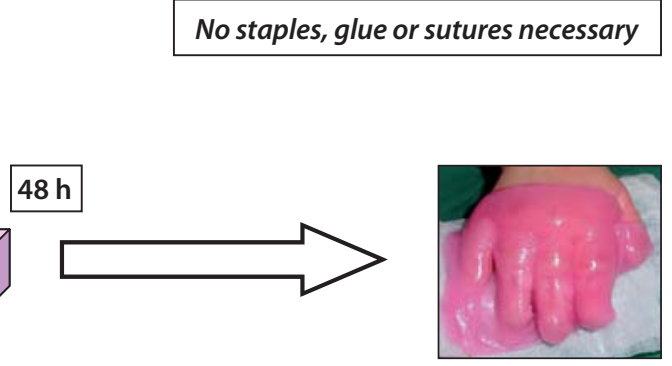

First cover burn patients construct molds over wounds

Fig. 1. Processing of a fetal cell bank and TEP. One fetal skin donation of approximately 12 weeks of gestation can be expanded in tissue culture to develop MCB and WCB. Cells from frozen WCB can be used for direct seeding onto collagen sponges for rapid delivery to patients (approx. 48 h). Over 270 million biological bandages can be developed from $1 \mathrm{MCB}$ and provide first cover of burns in thousands of patients.

tained. High consistency in fetal cell banking can be achieved due to the minimum nutrient requirements of fetal cell cultures. In contrast with mesenchymal stem cells, fetal cells do not require feeder layers for growth nor growth factors for differentiation. For skin tissue-engineered products (TEP), many products to date use a pool of multiple donors for a batch of cells. The differences between donors would not be as important, since many donors could be used. There is low heterogeneity between fetal donors for skin cell banks established in the same manner (large-scale expansion). Cell counts, protein determination and gene expression analysis are useful tools to assess the consistency of the cell banks when there is only one unique donor for skin TEP. Limits of variation for these assays specific for each cell type will need to be established internally to define the consistency of the process. For therapeutic use, fetal cells can be used up to two thirds of their life span in an out-scaling process. These overall criteria would be sufficient for limited preclinical trials in a university situation. However, if the goal is to develop a product used on a large-scale or a multicentric basis, assessment of the cell-derived product should not be restricted to description parameters such as protein concentration, but should include a functional assay. Furthermore, the activity of the final product is likely to be due to synergistic effects of multiple proteins, which cannot be assessed by individual protein concentration or activity. 


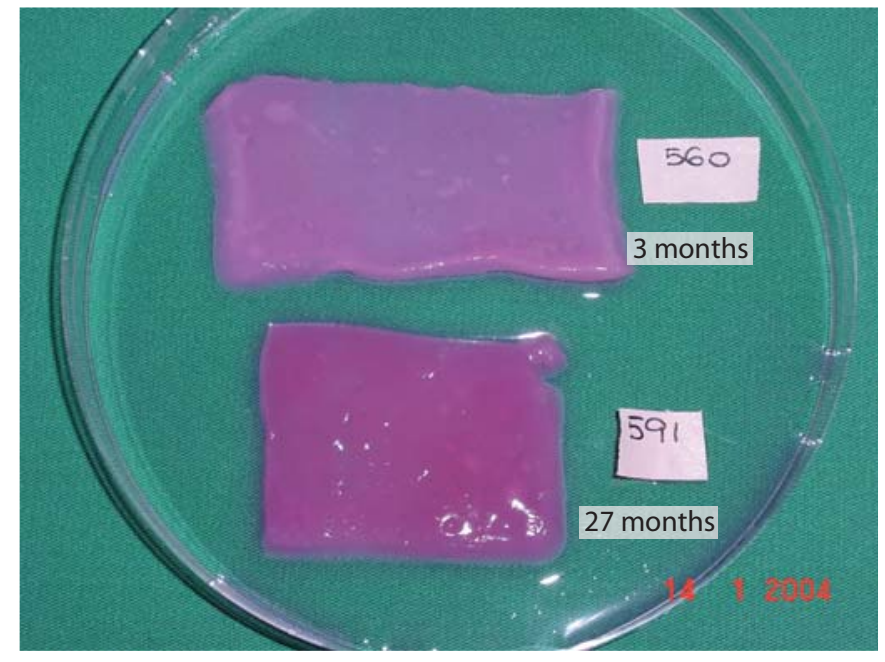

Fig. 2. Stability of skin biological bandages (TEP). Scaffolds [fetal cells were seeded at a density of 2,500 cells $/ \mathrm{cm}^{2}$ on equine collagen scaffolds (Baxter Tissue Fleece ${ }^{\circledR}$ )] were cultivated a few days and then conserved at different temperatures to observe the stability of the construct and the cellular viability for $1-4$ weeks $(24,4,-20$

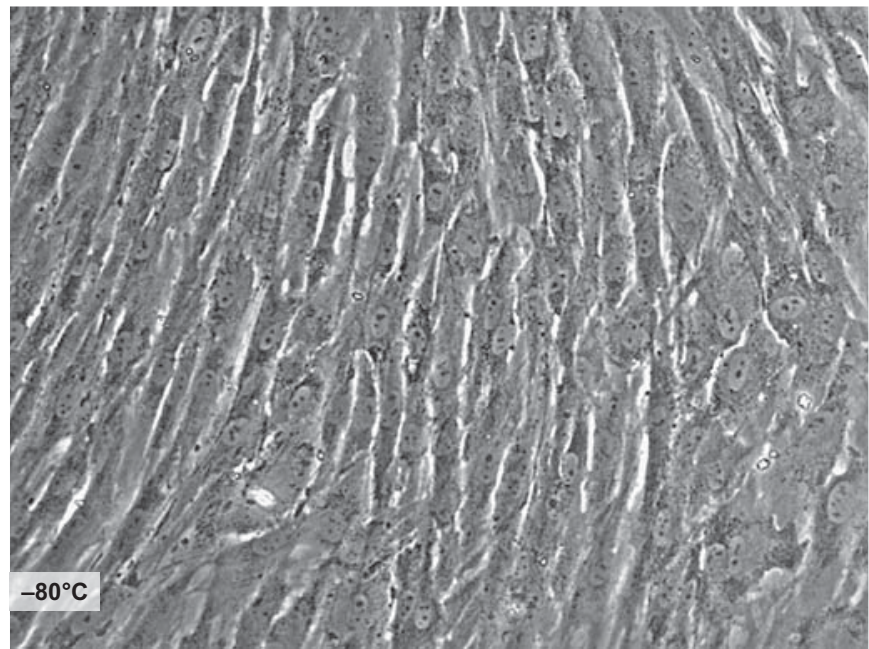

and $-80^{\circ} \mathrm{C}$ ) and up to 2 years for frozen constructs. Cells could be easily grown from constructs at all temperatures for up to 1 month and from frozen constructs at $-80^{\circ} \mathrm{C}$ for up to 27 months (cell morphology $100 \times$ ).
Fig. 3. Clinical use of skin biological bandages (TEP). Fetal skin construct application. Second- and third-degree burn on the hand (a) with escarotomy performed at 7 days (b) and fetal skin construct application enveloping all digits (c). Total closure and repigmentation seen at 20 days after therapy (d). Scale bar $=1 \mathrm{~cm}$.
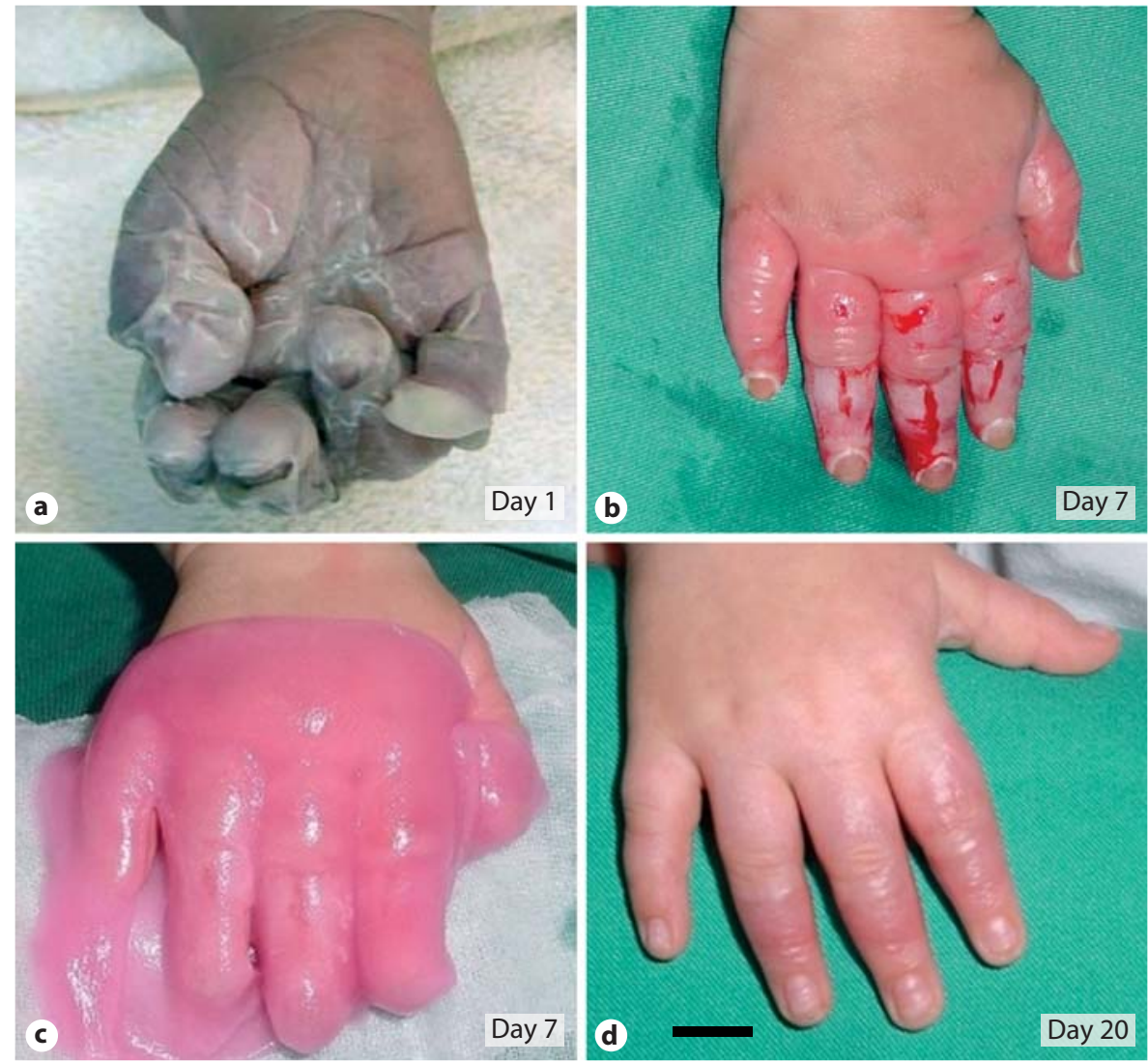

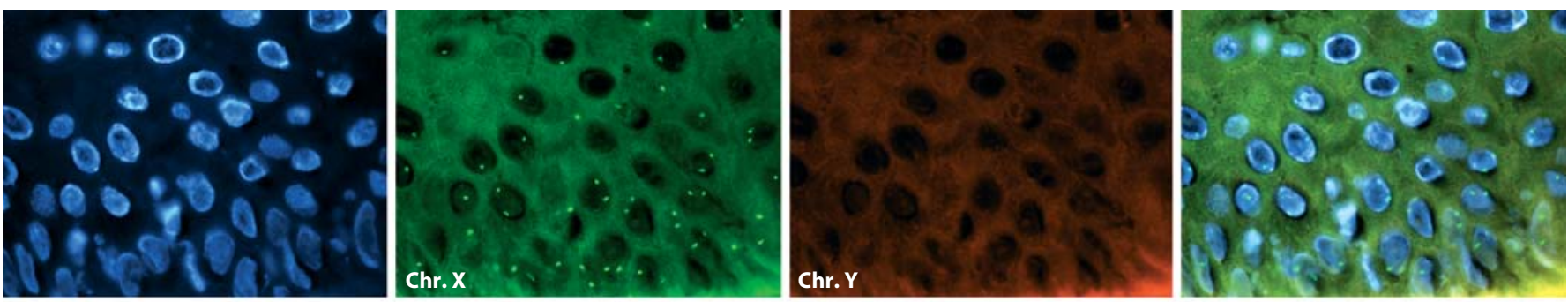

Dermis
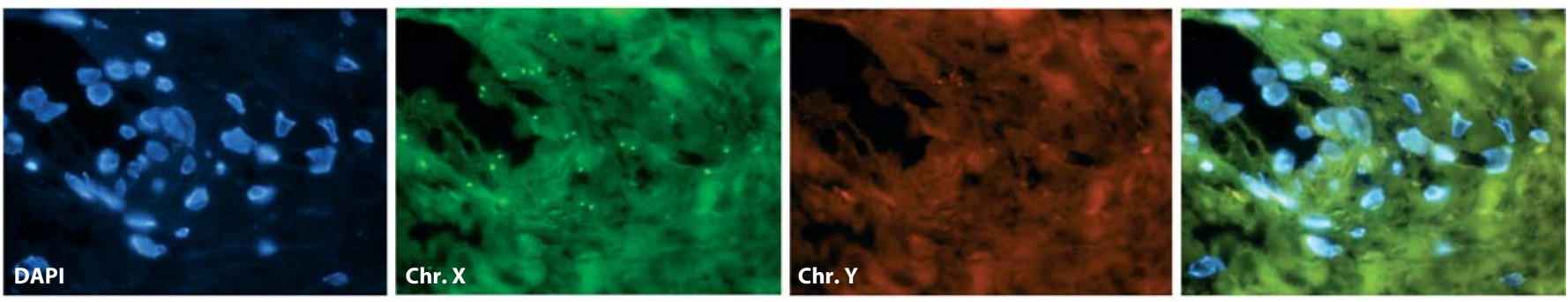

Cultured fetal skin cells - male donor
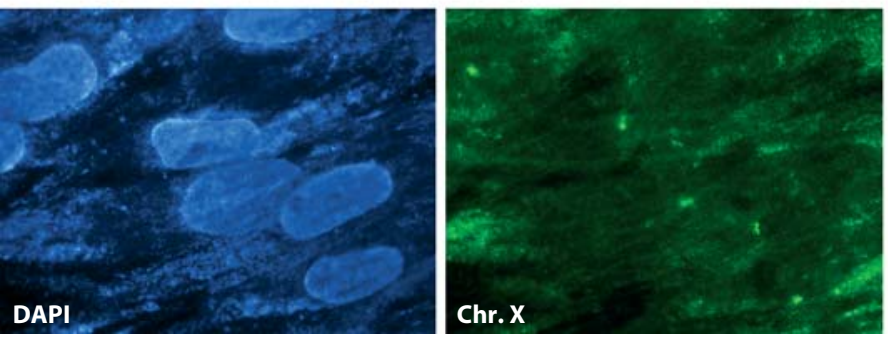

Fig. 4. Fluorescence in situ hybridization (FISH) for presence of fetal cells. As the fetal cells came from a male donor, the FISH technique was used to observe if there was any incorporation into 1 female recipient 6 months after therapy. A full-thickness biopsy was taken in the area that was burned at third degree and where a total of 5 fetal constructs were applied. The biopsy represented approximately 2,500 epidermal cells and 3,500 dermal cells. The whole surface was screened by FISH, with no cells found to have

As we have seen, each element necessary to produce a successful TEP needs to be verified for safety and consistency in the development. Cell choice for TEP is of utmost importance, and progress to assure the consistency will be necessary before allowing preclinical trials. Using only one fetal organ donation, it is possible to develop extensive MCB and WCB. Fetal cells, as an already differentiated lineage, need low nutritional requirements (that is, no feeder layers or external growth factors) to establish a fully defined consistent cell bank and can easily be assessed for safety assuring an interesting cell choice for TEP.

Fetal Skin Tissue Engineering
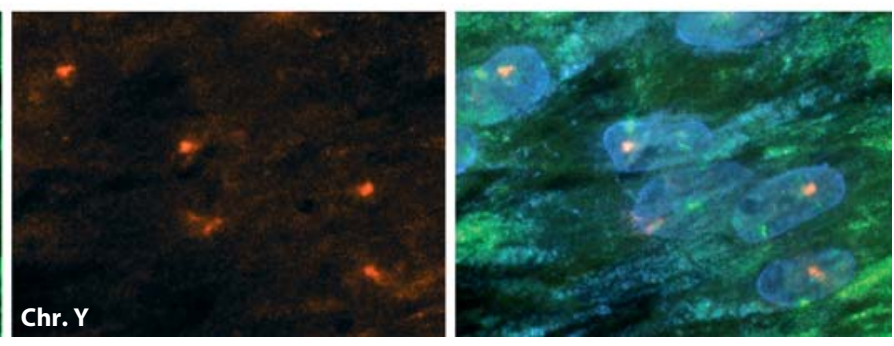

a Y chromosome. For comparison, a total of 200 cells were analyzed in the epidermis and 200 cells in the dermis to verify female karyotype (cell morphology $100 \times$ ). In the epidermis, $79 \%$ of the cells contained 1 or $2 \mathrm{X}$ chromosome-specific spots, whereas in the dermis, this proportion reached $83 \%$. On average, the number of X spots per cell nucleus was 1.17, which is consistent with a diploid pattern (XX karyotype) on 4- $\mu \mathrm{m}$ thick histologic sections, where most cell nuclei are in fact truncated.

WCB can be used to develop consistent TEP as depicted in figure 1. Cells from 1 vial of frozen WCB can be directly seeded on $9 \times 12 \mathrm{~cm}$ collagen sponge. These can be used directly on the patient after $48 \mathrm{~h}$ of incubation at $37^{\circ} \mathrm{C}$ and $5 \% \mathrm{CO}_{2}$. Many constructs can be prepared in a minimal amount of time, which could be used in the hospital's burn center. These biological constructs have been shown to be highly stable. Positive cell growth was seen when scaffolds were seeded with fetal cells at a density of 2,500 cells $/ \mathrm{cm}^{2}$ on equine collagen scaffolds (Baxter Tissue Fleece ${ }^{\circledR}$ ), cultivated a few days and then conserved at different temperatures to observe the stability of the con-

Skin Pharmacol Physiol 2009;22:63-73 
struct and the cellular viability for $1-4$ weeks $(24,4,-20$ and $-80^{\circ} \mathrm{C}$ ) and up to 2 years for frozen constructs. Cells could be easily grown from constructs at all temperatures for up to 1 month and from frozen constructs at $-80^{\circ} \mathrm{C}$ for up to 27 months without any conservative or freezing solution added (fig. 2).

\section{TEP for Clinical Use}

Constructs can be prepared from off-the-shelf WCB frozen vials of fetal skin cells by incubation for $48 \mathrm{~h}$ before delivery to the patient. These biological constructs can be easily made in large numbers, allowing immediate use for first cover of burns and wounds. Up until now, cadaver skin and de-epidermized pig skin have been the primary cover for burn patients. This process is a necessity to assure minimal liquid loss and infection of the patient. Burn patients continue to lose fluids until their wounds are covered. Wounds may be covered using ointment and a dressing, however, for more severe wounds a skin graft may be needed. Skin grafts are a major complication for patients that are not strong enough for surgery, and severely burned patients may not have enough healthy skin to donate. When a patient does not have enough healthy skin to harvest, temporary coverings of cadaver skin can be used, if available. As with all donor organs, cadaver skin is in short supply worldwide. Most importantly, this donor skin must be thoroughly screened to ensure that it is free of infectious agents. Any type of TEP that is offthe-shelf would therefore be an advantage in burn management. These products can prove to be life-saving for many burn victims.

In a study including 8 pediatric burn patients, time to healing for the burns was $14.3 \pm 9.15$ days after the first construct application. In all 8 burned patients, significant pain relief was noticed following application of the first construct. This was particularly striking in small children such as patient 1 (fig. 3). The patient presented with a liquid burn of the hand showing major tissue damage and signs of chronic pain (such as sleeping problems and irritability). Following the first application, all parents reported significant change in the overall behavior of their child. Esthetic and functional results were excellent in all children with burns with major improvement in the delay and quality of skin repair seen as opposed to techniques of traditional mesh or split grafting or autografting with cell cultures. In all cases, new skin showed high elasticity, improved color and no to little hypertrophic granulation tissue or cheloid formation. Moreover, a recovery of skin

pigmentation was observed, especially in patients with dark skin $[13,14]$. These were surprising results, since the study design was intended to only prepare the wound site with fetal cell constructs of pediatric burn patients that require autografting. The rapid wound closure of approximately 14 days in these patients with the fetal cell constructs eliminated the secondary grafting procedure normally necessary.

This wound closure does not seem to be associated with an actual grafting of the fetal cells into the patient. Biopsies taken on third-degree burn sites at 6 months after treatment were analyzed using the FISH technique and show that donor fetal skin cells were not incorporated into the receiver skin (fig. 4).

\section{Conclusions}

Overall, it is important to have a safe and effective means for enhancing the healing of wounds. Processing of cells and their delivery systems need to be easy, as does the verification of consistency of both the cells and the final product. Fetal skin cells provide an interesting alternative to autologous cells, stem cells, mesenchymal cells and neonatal foreskin cells (the most frequently used cell types to date), since they fulfill these requirements.

Even under the most optimal conditions, adult cutaneous repair results in scar. Thus, fetal skin represents the ideal paradigm of all tissue repair due to its inherent ability to repair through regeneration rather than scar. More importantly, its clinical use has been shown to alleviate painful autografting and prolonged treatment regimens and to be one step closer to 'perfect skin repair'.

References

Skin Pharmacol Physiol 2009;22:63-73

\footnotetext{
1 Limat A, Mauri D, Hunziker T: Successful treatment of chronic leg ulcers with epidermal equivalents generated from cultured autologous outer root sheath cells. J Invest Dermatol 1996;107:128-135.

-2 Kuroyanagi Y, Yamada N, Yamashita R, Uchinuma E: Tissue-engineered product: allogeneic cultured dermal substitute composed of spongy collagen with fibroblasts. Artif Organs 2001;25:180-186.

-3 Ichioka A, Kouraba S, Sekiya S, Ohura N, Nakatsuka T: Bone marrow-impregnated collagen matrix for wound healing: experimental evaluation in a microcirculatory model of angiogenesis, and clinical experience. Br J Plast Surg 2005;58:1124-1130.
}

Applegate/Scaletta/Hirt-Burri/Raffoul/ Pioletti 
4 Kaviani A, Perry T, Dzakovic A, Jennings RW, Ziegler MM, Fauza DO: The amniotic fluid as a source of cells for fetal tissue engineering. J Pediatr Surg 2001;36:1662-1665.

$\checkmark 5$ Kaviani A, Perry T, Burnes CM, Oh JT, Ziegler MM, Fishman SJ, Fauza DO: The placenta as a cell source in fetal tissue engineering. J Pediatr Surg 2002;37:995-999.

6 Jones I, Currie L, Martin R: A guide to biological skin substitutes. Br J Plast Surgery, 2002;55:185-193.

-7 Liu Y, Dulchavsky PA, Gao X, Kwon D, Chopp M, DulchavskyS, Gautam SC: Wound repair by bone marrow stromal cells through growth factor production. J Surg Res 2006; 136:336-341.

$>8$ Badiavas EV, Falanga V: Treatment of chronic wounds with bone marrow-derived cells. Arch Dermatol 2003;139:510-516.

-9 Nishimoto S, Oyama T, Matsuda K: Simultaneous concentration of platelets and marrow cells: a simple and useful technique to obtain source cells and growth factors for regenerative medicine. Wound Repair Regen 2007;15: 156-162.

10 Hasegawa T, Suga Y, Mizoguchi M, Ikeda S, Ogawa H, Kubo K, Matsui H, Kagawa S, Kuroyanagi Y: Clinical trial of allogeneic cultured dermal substitute for the treatment of intractable skin ulcers in 3 patients with recessive dystrophic epidermolysis bullosa. J Am Acad Dermatol 2003;50:803-804.

-11 Kashiwa N, Ito O, Ueda T, Kubo K, Matsui H, Kuroyanagi Y: Treatment of full-thickness skin defect with concomitant grafting of 6fold extended mesh auto-skin and allogeneic cultured dermal substitute. Artif Organs 2004;28:444-450.

$\checkmark 12$ Hohlfeld J, de Buys Roessingh A, Hirt-Burri N, Chaubert P, Gerber S, Scaletta C, Hohlfeld $\mathrm{P}$, Applegate LA: Tissue engineered fetal skin constructs for paediatric burns. Lancet 2005; 366:840-842.

13 de Buys Roessingh A, Hohlfeld J, Scaletta J, Hirt-Burri N, Gerber S, Hohlfeld P, Gebbers JO, Applegate LA: Development, characterization and use of a fetal skin cell bank for tissue engineering in wound healing. Cell Transplant 2006;15:823-834.
14 Lukish JR, Eichelberger MR, Newman KD, Pao M, Nobuhara K, Keating M, Golonka N, Pratsch G, Misa V, Valladares E, Johnson P, Gilbert JC, Powell DM, Hartman GE: The use of a bioactive skin substitute decreases length of stay for pediatric burn patients. J Pediatr Surg 2001;36:1118-1121.

15 Boyd M, Flaza M, Johnson PA, St Clair Roberts J, Kemp P: Integration and persistence of an investigational human living skin equivalent (ICX-SKN) in human surgical wounds. Regen Med 2007;2:363-370.

16 Cass DL, Meuli M, Adzick NS: Scar wars: implications of fetal wound healing for the pediatric burn patient. Pediatr Surg 1997;12: 484-489.

17 Ihara S, Motobayashi Y, Nagao E, Kistler A: Ontogenetic transition of wound healing pattern in rat skin occurring at the fetal stage. Development 1990;110:671-680.

18 Armstrong JR, Ferguson MWJ: Ontogeny of the skin and the transition from scar free to scarring phenotype during wound healing in the pouch young of the marsupial Monodelphis domestica. Dev Biol 1995;169:242260.

19 Dang C, Ting K, Soo C, Longaker MT, Lorenz HP: Fetal wound healing current perspectives. Clin Plast Surg 2003;30:13-23.

20 Bullard KM, Longaker MT, Lorenz HP: Fetal wound healing: current biology. World J Surg 2003;27:54-61.

21 Lorenz HP, Lin RY, Longaben MT, Whitby DJ, Adzick NS: The fetal fibroblast: the effector cell of scarless fetal skin repair. Plast Re constr Surg 1994;96:1251-1257.

22 Yang GP, Lim IJ, Phan TT, Lorenz HP, Longaker MT: From scar-less fetal wounds to keloids: Molecular studies in wound healing. Wound Repair Regen 2003;11:411-418.

23 Beanes SR, Dang C, Soo C, Ting K: Skin repair and scar formation: the central role of TGF- $\beta$. Exp Rev Mol Med 2003;5:1-11.

24 Lin RY, Adzick NS: The role of the fetal fibroblast and transforming growth factor- $\beta$ in a model of human fetal wound repair. Semin Pediatr Surg 1996;5:165-174.

25 Shah M, Foreman DM, Ferguson MWJ: Neutralisation of TGF- $\beta 1$ and TGF- $\beta 2$ or exogenous addition of TGF- $\beta 3$ to cutaneous rat wounds reduces scarring. J Cell Sci 1995;108: 985-1002.
26 Shah M, Foreman DM, Ferguson MW: Control of scarring in adult wounds by neutralising antibody to transforming growth factor $\beta$. Lancet 1992;339:213-214.

$27 \mathrm{Wu}$ L, Siddiqui A, Morris DE, Cox DA, Roth SI, Mustoe TA: Transforming growth factor $\beta 3$ (TGF beta 3 ) accelerates wound healing without alteration of scar prominence. Histologic and competitive reverse-transcription-polymerase chain reaction studies. Arch Surg 1997;132:753-760.

- 28 Kaiser S, Schirmacher P, Philipp A, Protschka M, Moll I, Nicol K, Blessing M: Induction of bone morphogenic protein-6 in skin wounds. Delayed re-epitheliazation and scar formation in BMP- 6 overexpressing transgenic mice. J Invest Dermatol 1998;111: 1145-1152.

29 Stelnicki EJ, Doolabh V, Lee S, Levis C, Baumann FG, Longaker MT, Mackinnon S: Nerve dependency in scarless fetal wound healing. Plast Reconstr Surg 2000;105:140147.

30 Christman KL, Fang Q, Kim AJ, Sievers RE, Fok HH, Candia AF, Colley KJ, Herradon G, Ezquerra L, Deuel TL, Lee RJ: Pleiotrophin induces formation of functional neovasculature in vivo. Biochem Biophys Res Commun 2005;332:1146-1152.

$31 \mathrm{Ng} \mathrm{KW}$, Khor HL, Hutmacher DW: In vitro characterization of natural and synthetic dermal matrices cultured with human dermal fibroblasts. Biomaterials 2004;25:28072818.

-32 Monjovent MO, Mathieu L, Hinz B, Applegate LA, Bourban PE, Zambelli PY, Manson JA, Pioletti D: Biocompatibility of Bioresorbable poly(L-lactic acid) composite scaffolds with human fetal bone cells. Tissue Eng 2005; 11:1640-1649.

33 Coulomb B, Friteau L, Baruch J, Guilbaud J, Chretien-Marguet B, Glicenstein J, Lebreton-Decoster C, Bell E, Dubertret L: Advantage of the presence of living dermal fibroblasts within in vitro reconstructed skin for grafting in humans. Plast Reconstr Surg 1998;101:1891-1903.

\begin{tabular}{l} 
C) Free Author \\
Copy - for per- \\
sonal use only \\
ANY DISTRIBUTION OF THIS \\
ARTICLE WITHOUT WRITTEN \\
CONSENT FROM S. KARGER \\
AG, BASEL IS A VIOLATION \\
OF THE COPYRIGHT. \\
Written permission to distrib- \\
ute the PDF will be granted \\
against payment of a per- \\
mission fee, which is based \\
on the number of accesses \\
required. Please contact \\
permission@ @ karger.ch \\
\hline
\end{tabular}

